\title{
HUBUNGAN OVERDISTENSI UTERUS DENGAN PERDARAHAN POST PARTUM DI RSUD BENGKULU TAHUN 2011
}

\author{
Suzana Fabella Putri, Yuliana Lubis, Susilo Damarini
}

Poltekkes Bengkulu, Jurusan Kebidanan Jl. Indragiri No.3 Bengkulu
Poltekkes Bengkulu, Jurusan Kebidanan Jl. Indragiri No.3 Bengkulu
Poltekkes Bengkulu, Jurusan Kebidanan Jl. Indragiri No.3 Bengkulu

\begin{abstract}
Haemorhagia are the main factor of dying mother. According to the Survei Kesehatan Rumah Tangga (SKRT) in 2007, dying mother causes by haemorhagia reached opver $60 \%$. Haemorhagia post partum which was happened in RSUD M. Yunus Bengkulu in the year 2011 had a significant number which are 208 cases. This researched have a purpose to known the relation between overdistention uterus and haemorhagia post partum in RSUD M. Yunus Bengkulu in the year 2011.Research conducted analytic survey with case control study design. The research was conducted in July until August 2012.The population are the mother who giving a birth which number 2.244 with quantity of sample are 416 with a ratio of 1:1 and separated by 208 sample taken as total sampling for the cases and 208 sample taken as systematic random sampling for the control. Data analysis has served in univariat and bivariat analysis. The result showed from 208 haemorhagia post partum cases, small percentage $(20,7 \%)$ of mother had makrosomia babies and a small portion $(12,5 \%)$ of mother who had gamelli babies and small amount $(6,2 \%)$ of mother got polyhidramnion case. The result of statistical test found a significant association between overdistention uterus with haemorhagia post partum. Expected for health workers to be more carefull and to have early identitifed of haemoraghia post partum risk factors so that can make great decision.
\end{abstract}

\begin{abstract}
Abstrak: Perdarahan merupakan faktor utama dalam kematian ibu. Menurut Survei Kesehatan Rumah Tangga (SKRT) tahun 2007 kematian ibu disebabkan oleh perdarahan mencapai 60\%. Kejadian perdarahan postpartum di RSUD dr. M. Yunus Bengkulu tahun 2011 masih cukup tinggi sebesar 208/224 x $100 \%=0.92$ kasus. Penelitian ini bertujuan untuk mengetahui hubungan overdistensi uterus dengan perdarahan post partum di RSUD. dr. M. Yunus Bengkul tahun 2011.Jenis penelitian adalah penelitian case control Populasi adalah seluruh ibu bersalin berjumlah 2.244 dengan jumlah sampel 416 dengan perbandingan 1:1 terbagi menjadi 208 diambil secara total sampling untuk kasus dan 208 diambil secara systematic random sampling untuk kontrol. Analisis data disajikan dalam analisis univariat dan bivariat.Berdasarkan hasil penelitian dari 208 kasus perdarahan post partum, sebagian kecil (20,7\%) ibu melahirkan bayi makrosomia, sebagian kecil (12,5\%) melahirkan bayi gamelli dan sebagian kecil $(6,2 \%)$ ibu dengan polyhidramnion. Hasil penelitian menunjukkan ada Hubungan ibu hamil yang mengalami overdistensi berpeluang untuk terjadinya pendarahan post partum.
\end{abstract}

Kata kunci : Perdarahan post partum, Overdistensi uterus

Angka Kematian Ibu (AKI) merupakan salah satu indikator sensitif untuk mengetahui derajat kesehatan suatu negara dan untuk mengukur tingkat kemajuan suatu bangsa. World Health Organization (WHO) melaporkan hampir $585.000 \mathrm{ibu}$ hamil dan ibu bersalin meninggal setiap tahunnya di seluruh dunia saat hamil atau bersalin, artinya setiap menit ada satu perempuan yang meninggal. Di Negara maju AKI pertahunnya hanya $27 / 100.000 \mathrm{ke}-$ lahiran hidup. Di Negara berkembang termasuk Indonesia AKI rata-rata dapat men- capai 18 kali lebih tinggi pada tahun 2007 yakni 480.000/100.000 kelahiran hidup (Dirjen Binkesmas, 2004). Menurut hasil Survei Demografi Kesehatan Indonesia (SKDI) tahun 2007 AKI di Indonesia menempati urutan pertama di ASEAN yaitu 228/100.000 kelahiran hidup. Angka ini ditargetkan menjadi 125/100 000 kelahiran hidup pada ak-hir tahun 2010 dan 102/100 000 ke-lahiran hidup pada akhir tahun 2015 (Depkes RI, 2009).

Menurut Survei Kesehatan Rumah Tangga (SKRT) tahun 2007 kematian ibu 
disebabkan oleh : perdarahan $(60 \%)$, disusul oleh pre-eklampsia $(22 \%)$ dan retensio plasenta (10\%). Perdarahan merupakan penyebab utama kematian ibu. Perdarahan dibagi menjadi 2 yaitu perdarahan antepartum dan perdarahan postpartum. Perdarahan terjadi setelah bayi lahir maupun pada masa nifas dinamakan perdarahan postpartum. Frekuensi perdarahan pospartum $4-15 \%$ dari seluruh persalinan. Perdarahan postpartum merupakan perdarahan lebih dari $500 \mathrm{cc}$ yang terjadi setelah anak lahir, faktor utama yang menyebabkan perdarahan postpartum ialah atonia uteri, retensio plasenta, perlukaan jalan lahir, dan sisa plasenta (Wiknjosastro,2002). Faktor pre-disposisi dari perdarahan postpartum ialah: overdistensi uterus yang terdiri dari : makrosomia (31\%), gamelli (6\%), anpolyhidramnion (3\%), grandemultipara (29\%), partuslama (13\%), obstetric operatif, narkosa, persalinan dengan tindakan (5\%), umur ibu ( $<20$ tahun dan $>35$ tahun) (7\%), kelainan pada uterus seperti pada mioma uteri( $2 \%)$, ketuban pecah dini (1\%), dan anemia (3\%) (Mochtar, 2007).

Provinsi Bengkulu pada tahun 2009 jumlah kematian Ibu sebanyak 42 orang yang terdiri dari kematian ibu hamil sebanyak 4 orang, kematian ibu bersalin sebanyak 35 orang dan kematian ibu nifas sebanyak 3 orang (Dinkes provinsi, 2009). Pada tahun 2010 jumlah kematian ibu sebanyak 45 orang yang terdiri dari kematian ibu hamil 9 orang, ibu bersalin 33 orang dan nifas 3 orang. Perdarahan pasca persalinan masih menjadi penyebab utama kematian ibu (Dinkes provinsi, 2010).

Menurut Dinas Kesehatan Kota Bengkulu pada tahun 2009 angka Kematian Ibu di tingkat kota adalah 80,14/100.000 kelahiran hidup atau 6 orang kematian ibu karena melahirkan dan pada tahun 2010 sebesar 50,7/100.000 kelahiran hidup atau 3 orang kematian ibu karena melahirkan. Salah satu penyebab kematian ibu yang berperan penting adalah perdarahan (Dinkes Kota, 2009).

Seperti yang telah disebutkan diatas, faktor predisposisi perdarahan postpartum yang paling sering ditemukan ialah overdistensi uterus yang terdiri dari makrosomia, gamelii dan polyhidramnion. Overdistensi uterus ialah peregangan uterus yang berlebihan sebagai akibat dari keadaankeadaan seperti makrosomia, gamelli dan polyhidramnion. Pada keadaan ini uterus cenderung mempunyai daya kontraksi yang jelek (Dees RI, 2007). Akibat terlalu teregangnya uterus yang diakibatkan oleh persalinan dengan makrosomia gamelli dan polihidramnion maka setelah bayi dan plasenta lahir serabut-serabut miometrium susah untuk mengecil atau menutup dan mengakibatkan uterus susah berkontaksi /kontaksi hipotonik sehingga menyebabkan terjadinya perdarahan postpartum (Wiknjosastro, 2006).

Berdasarkan hasil penelitian dari Badriyah (2011) mengenai "Pengaruh faktor resiko terhadap perdarahan postpartum" didapatkan hasil bahwa bayi besar, persalinan kembar dan partus lama merupakan faktor predisposisi terjadinya perdarahan post partum dengan nilai taraf signifikansi $(0,00<0,05)$. Penelitian lain dari J.D Hamlett mengenai "Acute recurrent polyhydramnios" didapatkan bahwa polyhidramnion mengakibatkan uterus mengalami overdistensi sehingga menyebabkan haemoragic postpartum atau perdarahan postpartum.

Dampak dari perdarahan pasca persalinan ini ibu bisa meninggal. Ketika terjadi perdarahan, ibu bisa mengalami syok dengan tanda-tanda vital semakin melemah hingga akhirnya mengakibatkan kematian. Untuk itu ibu dengan perdarahan postpartum perlu mendapatkan penanganan yang intensif.

Berdasarkan survey awal yang didapatkan peneliti di ruang kebidanan RSUD DR. M. Yunus Bengkulu pada bulan Januari - Desember 2011 terdapat 208 $(9,2 \%)$ kasus perdarahan postpartum dari 2244 persalinan, dimana dari 208 kasus per-darahan post partum tersebut terdapat 69 kasus bayi besar (33\%), 39 kasus persalinan kembar (18\%) dan 17 kasus polyhidramnion $(8,1 \%)$. Sedangkan data 
yang didapat di RS. Jitra Bayangkara Bengkulu pada tahun 2011 terjadi 17 $(1,6 \%)$ kasus perdarahan post partum dari 1022 persalinan, 22 kasus bayi besar , 10 kasus persalinan kembar, dan 7 kasus polyhidramnion.

Data diatas terlihat masih tingginya angka kejadian perdarahan postpartum di ruang kebidanan RSUD DR. M Yunus Bengkulu tahun 2011. Berdasarkan permasalahan tersebut, maka peneliti tertarik untuk melakukan penelitian yang berjudul "Hubungan overdistensi uterus dengan perdarahan postpartum di RSUD DR. M. Yunus Bengkulu tahun 2011”.

\section{BAHAN DAN CARA KERJA}

Jenis penelitian yang dilakukan secara survey analitik dengan rancangan penelitian case control dengan variable independen adalah overdistensi uterus (makrosomia, gamelli dan polyhidramnion) dan variable dependennya adalah kejadian perdarahan post partum dengan retrospectif. Populasi pada penelitian ini adalah seluruh ibu bersalin di ruang Mawar RSUD M. Yunus Bengkulu dari bulan Januari sampai bulan desember 2011 sebanyak 2244 ibu dengan kejadian perdarahan post partum sebanyak 208 orang. Sampel dalam penelitian ini terdiri dari kelompok kasus dan kelompok kontrol dengan perbandingan 1:1. Sampel pada kelompok kasus adalah ibu bersalin yang mengalami perdarahan postpartum sebanyak 208 orang dan diambil secara total sampling. Kelompok control adalah ibu bersalin yang tidak mengalami perdarahan post partum sebanyak 208 orang dan diambil secara systematic random sampling diambil setiap kelipatan 9 dari daftar populasi maka seluruh jumlah sampel sebanyak 416 kasus.

\section{HASIL}

\section{Hasil Univariat}

Analisis ini dilakukan untuk mendapatkan gambaran distribusi frekuensi masing-masing variabel baik variabel dependen yaitu perdarahan post partum dan variabel independen yaitu overdistensi uterus (makrosomia, gamelli dan polyhidramnion)di RSUD. Dr. M. Yunus Bengkulu tahun 2011.

Tabel 1. Distribusi Frekuensi makrosomia, gamelli dan polyhidramnion di RSUD. Dr. M. Yunus Bengkulu tahun 2011.

\begin{tabular}{lcccccc}
\hline \multicolumn{1}{c}{ Variabel } & Kasus & & kontrol & \multicolumn{2}{c}{ Jumlah } \\
\cline { 2 - 6 } & $\mathrm{N}$ & $\%$ & $\mathrm{~N}$ & $\%$ & $\mathrm{~N}$ & $\%$ \\
\hline Perdarahan post partum & 208 & 50 & 208 & 50 & 416 & 100 \\
Makrosomia & 43 & 20,7 & 26 & 12,5 & 69 & 16,6 \\
Gamelli & 26 & 12,5 & 13 & 6,2 & 39 & 1,9 \\
Polyhidramnion & 13 & 6,2 & 4 & 1,9 & 17 \\
\hline
\end{tabular}

Tabel 1 menjelaskan bahwa 208 orang ibu bersalin mengalami perdarahan postpartum, sebagian kecil ibu yang melahirkan bayi makrosomia (20,7\%), sebagian kecil lainnya $(12,5 \%)$ ibu yang melahirkan bayi gamelli, dan sebagian kecil $(6,2 \%)$ ibu dengan polyhidramnion

\section{Hasil Bivariat}

Analisis ini dilakukan untuk mengetahui hubungan variabel bebas dengan variable terikat dengan uji statistic chi square yang diolah dengan system komputerisasi. 
Tabel 2. Hubungan Makrosomia dengan Perdarahan Post Partum di RSUD. Dr. M. Yunus Bengkulu Tahun 2011.

\begin{tabular}{|c|c|c|c|c|c|c|c|c|}
\hline \multirow{3}{*}{ Makrosomia } & \multicolumn{4}{|c|}{ HPP } & \multirow{2}{*}{\multicolumn{2}{|c|}{ Jumlah }} & \multirow{3}{*}{$P$} & \multirow{3}{*}{ OR } \\
\hline & \multicolumn{2}{|c|}{$\mathrm{Ya}$} & \multicolumn{2}{|c|}{ Tidak } & & & & \\
\hline & $\mathrm{F}$ & $\%$ & $\mathrm{~F}$ & $\%$ & $\mathrm{~F}$ & $\%$ & & \\
\hline Makrosomia & 43 & 20,7 & 26 & 12,5 & 69 & 16,6 & & \\
\hline Tidak Makrosomia & 165 & 79,3 & 182 & 87,5 & 347 & 83,4 & 0,03 & 1,82 \\
\hline Total & 208 & 100 & 208 & 100 & 416 & 100 & & \\
\hline
\end{tabular}

Berdasarkan tabel 2 hasil analisis menunjukkan dari 208 kasus perdarahan post partum, sebagian kecil $(20,7 \%)$ ibu dengan perdarahan post partum yang melahirkan bayi makrosomia. Dari hasil uji statistic chi-square di dapat 0,03 , hal ini menunjukkan bahwa terdapat hubungan an- tara makrosomia dengan perdarahan post partum. Hasil nilai Odds Ratio sebesar 1,82 artinya ibu yang mengalami perdarahan post partum berpeluang 1,82 kali terjadi pada ibu yang melahirkan bayi makrosomia dari pada ibu yang tidak melahirkan bayi makrosomia.

Tabel 3. Hubungan Gamelli dengan Perdarahan Post Partum di RSUD. Dr. M. Yunus Bengkulu Tahun 2011.

\begin{tabular}{|c|c|c|c|c|c|c|c|c|}
\hline \multirow{3}{*}{ Gamelli } & \multicolumn{4}{|c|}{ HPP } & \multirow{2}{*}{\multicolumn{2}{|c|}{ Jumlah }} & \multirow{3}{*}{$P$} & \multirow{3}{*}{ OR } \\
\hline & \multicolumn{2}{|c|}{$\mathrm{Ya}$} & \multicolumn{2}{|c|}{ Tidak } & & & & \\
\hline & $\mathrm{F}$ & $\%$ & $\mathrm{~F}$ & $\%$ & $\mathrm{~F}$ & $\%$ & & \\
\hline Gamelli & 26 & 12,5 & 13 & 6,2 & 39 & 9,4 & \multirow{3}{*}{0,04} & \multirow{3}{*}{2,14} \\
\hline Tidak Gamelli & 182 & 87,5 & 195 & 93,8 & 377 & 90,6 & & \\
\hline Total & 208 & 100 & 208 & 100 & 416 & 100 & & \\
\hline
\end{tabular}

Berdasarkan tabel 3 hasil analisis menunjukkan dari 208 kasus perdarahan post partum sebagian kecil $(12,5 \%)$ ibu dengan perdarahan post partum yang melahirkan bayi gamelli. Dari hasil uji statistic chisquare di dapat 0,04 , hal ini menunjukkan bahwa terdapat hubungan antara gamelli dengan perdarahan post partum.. Hasil nilai Odds Ratio sebesar 2,14 artinya ibu yang mengalami perdarahan post partum berpeluang 2,14 kali terjadi pada ibu yang melahirkan bayi gamelli dari pada ibu yang tidak melahirkan bayi gamelli.

Tabel 4. Hubungan Polyhidramnion dengan Perdarahan Post Partum di RSUD. Dr. M. Yunus Bengkulu Tahun 2011.

\begin{tabular}{|c|c|c|c|c|c|c|c|c|}
\hline \multirow{3}{*}{ Polyhidramnion } & \multicolumn{4}{|c|}{ HPP } & \multirow{2}{*}{\multicolumn{2}{|c|}{ Jumlah }} & \multirow{3}{*}{$P$} & \multirow{3}{*}{ OR } \\
\hline & \multicolumn{2}{|c|}{$\mathrm{Ya}$} & \multicolumn{2}{|c|}{ Tidak } & & & & \\
\hline & $\mathrm{F}$ & $\%$ & $\mathrm{~F}$ & $\%$ & $\mathrm{~F}$ & $\%$ & & \\
\hline Polyhidramnion & 13 & 6,2 & 4 & 1,9 & 17 & 4,1 & & \\
\hline Tidak polyhidramnion & 195 & 93,8 & 204 & 98,1 & 399 & 95,9 & 0,04 & 3,40 \\
\hline Total & 208 & 100 & 208 & 100 & 208 & 100 & & \\
\hline
\end{tabular}

Berdasarkan tabel 4, hasil analisis menunjukkan dari 208 kasus perdarahan post partum sebagian kecil $(6,2 \%)$ ibu dengan perdarahan post partum yang melahirkan bayi polyhidramnion. Dari hasil uji statistic chi-square di dapat 0,04 , hal ini menunjukkan bahwa terdapat hubungan antara polyhidramnion dengan perdarahan post partum.. Hasil nilai Odds Ratio sebesar 3,40 artinya ibu yang mengalami perdarahan post partum berpeluang 3,40 kali terjadi pada ibu dengan polyhidramnion dari pada ibu yang tidak polyhidramnion.

\section{PEMBAHASAN}

\section{Hubungan Overdistensi Uterus dengan Perdarahan Post Partum}

Pada penelitian yang dilakukan oleh peneliti, sebagian kecil $(16,6 \%)$ ibu yang melahirkan bayi makrosomia, sebagian kecil $(9,4 \%)$ ibu yang melahirkan bayi gamelli dan sebagian kecil $(4,1 \%)$ ibu yang 
mengalami polyhidramnion. Hasil uji analisis bivariat menunjukkan adanya hubungan antara overdistensi uterus (makrosomia, gamelli dan polyhidramnion) dengan kejadian perdarahan post partum.

Perdarahan postpartum disebabkan oleh beberapa faktor diantaranya overdistensi rahim atau uterus yang terlalu teregang yang disebabkan persalinan dengan makrosomia, gamelli dan polihydramnion. Salah satu penyebab dari overdistensi uterus adalah bayi besar atau makrosomia. Dari hasil penelitian didapatkan sebagian kecil $(20,7 \%)$ ibu yang melahirkan bayi makrosomia mengalami perdarahan post partum. Pada ibu yang melahirkan bayi makrosomia mempunyai resiko terjadi perdarahan post partum karena pada keadaan makrosomia uterus mengalami peregangan yang berlebihan atau overdistensi uterus akibat berat badan bayi yang besar, menyebabkan otot-otot uterus susah untuk menciut dan verkontraksi sehingga mengakibatkan perdarahan.

Sebagaimana kita ketahui bahwa aliran darah uteroplasenta selama masa kehamilan adalah 500-800 ml/menit, sehingga ketika uterus itu sulit verkontraksi selama beberapa menit, menyebabkan kehilangan darah yang sangat banyak sedangkan volume darah manusia hanya berkisar 5-6 liter. Akibat terlalu regangnya uterus yang diakibatkan oleh makrosomia maka setelah bayi dan plasenta lahir kontraksi uterus akan terganggu dan akan mengakibatkan uterus tidakmampu verkontraksi segera setelah plasenta lahir (Depkes RI, 2000).

Penelitian ini sejalan dengan penelitian sebelumnya yang dilakukan oleh Yono (2007), di RS. Pringadi Medan menunjukkan terdapat hubungan antara ibu yang mengalami perdarahan postpartum dengan makrosomia. Nilai OR 2,248 artinya bayi makrosomia berisiko mengalami perdarahan post partum 2,248 x lebih besar dibandingkan bayi yang tidak makrosomia.

Faktor lain yang menyebabkan terjadinya overdistensi uterus ialah gamelli atau bayi kembar. Dari hasil penelitian di- dapatkan sebagian kecil (12-,5\%) ibu yang melahirkan bayi gamelli mengalami perdarahan post partum. Ibu yang melahirkan bayi gamelli rentan mengalami perdarahan post partum karena pada keadaan gamelli dengan janin yang lebih dari satu meningkatkan perubahan anatomis pada bagian uterus dan membuat ukuran uterus menjadi lebih besar, sehingga menyebabkan pembuluh-pembuluh darah pada uterus susah untuk berkontraksi (his tidak baik) dan pada akhirnya menyebabkan perdarahan terus menerus setelah bayi lahir.

Pada persalinan gamelli terjadi gangguan kontraksi otot rahim yang menyebaban rahim susah untuk berkontraksi dan menimbulkan perdarahan postpartum. Seorang wanita dengan gamelli mempunyai volume darah yang lebih besar dan mendapatkan beban ekstra pada sistem kardiovaskuler, peregangan otot rahim yang menyebabkan gangguan kontraksi dapat menyebabkan perdarahan postpartum (Joseph, 2010).

Pada persalinan kembar (gamelli) distensi uterus berlebihan sehingga melewati batas toleransi dan sering kali menimbulkan perdarahan. Secara umum derajat perubahan fisiologis maternal lebih besar pada persalinan kembar dibandingkan dengan persalinan tunggal. Perluasan volume darah maternal normal adalah $500 \mathrm{ml}$ dan pada persalinan kembar hal ini bisa menjadi 2 kali lipat. Pada persalinan kembar rata-rata kehilangan darah setelah bayi lahir pada persalinan pervaginam adalah 950-1000 $\mathrm{ml}$ atau hampir $500 \mathrm{ml}$ lebih banyak dari persalinan bayi tunggal (Patrick, 2011).

Penelitian ini sejalan dengan penelitian yang dilakukan oleh Badriyah (2011), dengan judul faktor- faktor risiko perdarahan post partum di RS. Syarifah Bangkalan dengan salah satu faktor risiko gamelli. Hasil penelitian menunjukkan terdapat hubungan antara gamelli dengan perdarahan post partum, dan gamelli merupakan salah satu faktor risiko perdarahan post partum. 
Overdistensi selain disebabkan oleh makrosomia dan gamelli juga disebabkan oleh polyhidramnion. Dari hasil penelitian didapatkan sebagian kecil $(6,2 \%)$ ibu dengan polyhidramnion mengalami perdarahan post partum. Pada ibu dengan polyhidramnion mempunyai resiko perdarahan post partum karena dengan cairan ketuban yang berlebihan menyebabkan uterus terlalu teregang sehingga membuat otot-otot uterus susah untuk melakukan kontraksi dimana seharusnya setelah bayi atau placenta lahir otot-otot uterus harus segera berkontraksi untuk menghindari terjadinya perdarahan. Selain itu polyhidramnion tidak jarang menimbulkan nyeri pada ibu.

Pada keadaan polyhidramnion tidak jauh berbeda dengan keadaan makrosomia dan gamelli. Pada keadaan ini cairan ketuban melebihi batas normal atau melebihi $2000 \mathrm{ml}$, sehingga menyebabkan uterus atau rahim ibu menjadi teregang akibat air ketuban yang berlebihan tersebut dan tidak jarang menimbulkan nyeri. Uterus yang mengalami peregangan secara berlebihan seperti pada keadaan polyhidramnion cenderung memiliki daya kontraksi yang jelek sehingga menyebabkan otot-otot uterus

\section{DAFTAR KEPUSTAKAAN}

Bagian Obstetri dan Ginekologi FK UNPAD.1983. Obstetri Fisiologi. Bandung

Badriyah. 2011. Pengaruh faktor resiko terhadap perdarahan postpartum, diakses dari http:// digilib. Poltekkesdepkes -sby.ac.id pada tanggal 04 Juni 2012

Cholil. 2005. Faktor-faktor yang mempengaruhi kejadian post partum, diakses dari http://wordpress.com pada tanggal 10 April 2012

Depkes RI. 2009. Profil Kesehatan Republik Indonesia. Jakarta

Dinkes Propinsi Bengkulu. 2010. Profil Kesehatan Provinsi Bengkulu, Bengkulu

Dinkes Kota Bengkulu. 2010. Profil Kesehatan Kota Bengkulu, Bengkulu

Fadlun, Feryanto Ahmad. 2011. Asuhan Kebidanan Patologis.Salemba Medika. Jakarta

Hallohazkiya. 2009, Polyhidramnion, diakses dari http://multiply. com/ journal.item diakses pada tanggal 10 April 2012

Joseph HK, Nugroho M. 2010. Catatan Kuliah Ginekologi dan Obstetri (obsgyn).

Yogyakarta : Nuha Medika susah untuk mengecil dan menyebabkan perdarahan pasca bayi lahir (Fadlun,2011).

Penelitian ini sejalan dengan penelitian yang dilakukan oleh Rahardjo (2011), yang meneliti tentang "faktor-faktor yang berhubungan dengan kejadian perdarahan postpartum" di RSUP dr. M. Djamil Padang, dengan hasil ada hubungan yang bermakna antar kejadian polyhidramnion dengan perdarahan postpartum.

\section{KESIMPULAN}

Berdasarkan pembahasan dari hasil penelitian didapatkan bahwa ada hubungan yang bermakna antara overdistensi uterus dengan perdarahan post partum di ruang kebidanan RSUD DR M. Yunus Bengkulu. Diharapkan kepada petugas kesehatan khususnya bagi petugas kebidanan untuk dapat mengidentifikasi secara dini faktor risiko dan kemungkinan dari kejadian overdistensi uterus (makrosomia, gamelli dan polyhidramnion) sehingga dapat membuat keputusan klinik yang tepat dalam upaya terminasi kehamilan untuk usaha preventif perdarahan post partum.

Manuaba. 2006. Ilmu Kebidanan, Penyakit Kandungan dan Keluarga Berencana untuk Pendidikan Bidan. EGC. Jakarta

Mochtar. 2007. Sinopsis Obstetri. EGC. Jakarta

Notoatmodjo, S. 2010. Metodologi Penelitian Kesehatan. Jakarta : Rineka Cipta

Patrick. 2011. Kehamilan Kembar (Gamelly), diakses dari http://Hendraqliquerz/blogspot.com/2011/ma kalah gamelly diakses pada tanggal 26 April 2012

Rahardjo. 2011. Faktor-faktor yang berhubungan dengan kejadian perdarahan postpartum. diakses dari www.jurnalkesmas.com/index.php/kesmas/art icle pada tanggal 4 Juni 2012

Saifuddin, AB dkk. 2005. Buku Acuan Nasional Pelayanan Kesehatan Maternal dan Neonatal. Jakarta : JNPKKR-POGI

Sastrawinata.1998.Obstetri Patologi. Ellstar Offset, Bandung

Sekartini, 2007. Makrosomia , diakses dari http:// noeytamalan revolute.blogspot.com, 02 Maret 2011 
176 Jurnal Media Kesehatan, Volume 5, Nomor 2, Desember 2012, hlm 101-205

Sopiyudin. 2010. Besar Sampel dan Cara Pengambilan Sampel. Salemba Medika. Jakarta

Saepudin. 2006. Ilmu Kebidanan. Yayasan Bina Pustaka Sarwono Prawirohardjo. Jakarta
Yono. 2007. Faktor penyebab perdarahan postpartum. diakses dari www.jurnalkebidanan.com/php/kebidanan /article pada tanggal 15 Juni 2012 